\title{
The efficacy and safety of panitumumab in the treatment of patients with metastatic colorectal cancer: a meta-analysis from five randomized controlled trials
}

\author{
This article was published in the following Dove Press journal: \\ Drug Design, Development and Therapy \\ 7 August 2015 \\ Number of times this article has been viewed
}

\section{Ruo-feng Liang' \\ Lei-lei Zheng ${ }^{2}$}

'General Department, University Hospital, Affiliated to Zhejiang Science-Technology University, Hangzhou, People's Republic of China; ${ }^{2}$ Department of Psychiatry, Second Affiliated Hospital of Zhejiang University School of Medicine, Hangzhou, People's Republic of China
Correspondence: Lei-lei Zheng Department of Psychiatry, Second Affiliated Hospital of Zhejiang University School of Medicine, 88 Jiefang Road, Hangzhou 310009, People's Republic of China

Tel $+8657 \mid 87783773$

Fax +86 57I 8706800 I

Email zhengleileihz@I26.com
Background: The efficacy of adding panitumumab to chemotherapy remains controversial in the treatment of metastatic colorectal cancer (mCRC). Thus, we conducted this meta-analysis to assess the efficacy and safety of this combination regimen in patients with mCRC.

Methods: The PubMed, Embase, and Web of Science databases were comprehensively searched. Eligible studies included randomized controlled trials (RCTs) that estimated the efficacy of panitumumab with or without chemotherapy in the treatment of patients with mCRC. Hazard ratio (HR), risk ratio (RR), and 95\% confidence intervals (CIs) were calculated, and heterogeneity was tested using $I^{2}$ statistics.

Results: Four studies involving a total of 3,066 patients were included in this meta-analysis. The addition of panitumumab to chemotherapy significantly improved progression-free survival (PFS) $(\mathrm{HR}=0.84,95 \% \mathrm{CI}=0.78-0.91, P=0.000)$ and the objective response rate (ORR) ( $\mathrm{RR}=2.18,95 \% \mathrm{CI}=1.13-4.22, P=0.021)$ compared to chemotherapy alone, but no effect was noted on overall survival (OS) $(\mathrm{HR}=0.97,95 \% \mathrm{CI}=0.89-1.05, P=0.402)$. Subgroup analysis based on KRAS gene status revealed that the combined therapy significantly improved PFS $(\mathrm{HR}=0.71,95 \% \mathrm{CI}=0.57-0.88, P=0.002)$ and $\mathrm{ORR}(\mathrm{RR}=2.43,95 \% \mathrm{CI}=1.21-4.90, P=0.013)$ in patients with wild-type $K R A S$ tumors. Irinotecan-based chemotherapy plus panitumumab significantly prolonged PFS in patients with $\mathrm{mCRC}(\mathrm{HR}=0.84,95 \% \mathrm{CI}=0.76-0.94, P=0.002)$. The combined treatment also increased the incidence of grade $3 / 4$ adverse events.

Conclusion: This meta-analysis indicates that the combination of panitumumab and chemotherapy effectively improved PFS and ORR, but it did not prolong OS. However, as the number of studies in the meta-analysis was limited, more large-scale, better-designed RCTs are needed to assess the combination of panitumumab and chemotherapy.

Keywords: panitumumab, chemotherapy, metastatic colorectal cancer, meta-analysis

\section{Introduction}

Colorectal cancer ranks as the third most common cancer worldwide, as approximately 1 million new cases are diagnosed annually. ${ }^{1}$ The median overall survival (OS) of patients with metastatic colorectal cancer $(\mathrm{mCRC})$ has been improved considerately in recent decades, ${ }^{2,3}$ mainly because of the introduction of new chemotherapeutic agents and targeted therapies. ${ }^{4,5}$

Chemotherapeutic agents are widely used for patients with advanced disease to prolong survival, control symptoms, and improve the quality of life. ${ }^{6-9}$ As the foundation of chemotherapy in advanced $\mathrm{mCRC}$, oxaliplatin and irinotecan have exhibited clinical effects in the treatment of mCRC. Human epidermal growth factor receptor (EGFR) 
is a transmembrane cell surface glycoprotein ${ }^{10}$ that plays an important role in the proliferation and metastasis of colorectal cancer by activating various signaling pathways. ${ }^{11}$ Thus, EGFR has become the primary therapeutic target for this cancer. Panitumumab is a fully human monoclonal antibody directed against EGFR, and its activity in terms of a survival benefit has been proven. ${ }^{12}$ However, panitumumab appears to produce different clinical outcomes in the treatment of mCRC when combined with different chemotherapeutics. Beneficial effects were observed when panitumumab was combined with irinotecan-based chemotherapy, and negative effects were noted when the drug was combined with oxaliplatin-based chemotherapy. Moreover, the interaction between oxaliplatin and panitumumab remains unknown.

The KRAS gene status is considered a predictive marker of anti-EGFR monoclonal antibodies. Previous research illustrated that patients with mutant $K R A \mathrm{~S}$ did not experience a clinical benefit of anti-EGFR therapy. ${ }^{13}$ The aim of this metaanalysis was to explore the efficacy and toxicities of adding panitumumab to chemotherapy in patients with $\mathrm{mCRC}$ according to $K R A S$ status and assess the efficacy of panitumumab in combination with different chemotherapeutic partners.

\section{Methods}

\section{Literature search and inclusion criteria}

The PubMed, Embase, and Web of Science databases were searched to identify studies (published before December 24, 2014) on the addition of panitumumab to chemotherapy in the treatment of mCRC. The following search terms were used: ("panitumumab" [Supplementary Concept] OR "panitumumab" [All Fields]) AND ("secondary" [Subheading] OR "secondary" [All Fields] OR "metastatic" [All Fields]) AND ("colorectal neoplasms" [MeSH Terms] OR ("colorectal" [All Fields] AND “neoplasms" [All Fields]) OR “colorectal neoplasms" [All Fields] OR ("colorectal" [All Fields] AND “cancer” [All Fields]) OR “colorectal cancer" [All Fields]). The search was limited to human studies and randomized controlled trials (RCTs). No language restriction was imposed. We also manually searched the reference lists of the included studies until no potentially eligible articles could be identified. Studies that met the following inclusion criteria were included: 1) study design, RCT; 2) study population, $\geq 18$ years old with a diagnosis of adenocarcinoma of the colon or rectum; 3 ) intervention, chemotherapy with or without panitumumab; and 4) outcome measure, OS, progression-free survival (PFS), and overall response rate (ORR). If duplicate data were presented in several studies, only the most informative or complete articles were included.

\section{Data extraction and outcome measures}

Two authors independently extracted the following data from each study: first author, treatment regimen, the number of patients (intervention/control), age range or mean age of the patients, type of blinding, type of controls, hazard ratios (HRs) with 95\% confidence intervals (CIs) for OS, PFS, ORR, and the incidence of adverse events. A standardized Excel file was used for data extraction. Disagreements between the investigators were resolved by discussion and consensus. The primary outcome was PFS. Secondary outcomes included OS, ORR, and the incidence of adverse events.

\section{Quality assessment}

The methodological quality of the studies was independently scored by Ruo-feng Liang and Lei-lei Zheng using a validated Jadad five-point scale. ${ }^{14}$ The scale consists of three items describing randomization ( $0-2$ points), masking ( $0-2$ points), and dropouts and withdrawals ( $0-1$ point) in the report of an RCT. ${ }^{14}$ A score of 1 point is given for each of the points described. An additional point is given when the method of randomization and/or blinding is given and appropriate, whereas a point is deducted when the method is inappropriate. The quality scale ranges from 0 to 5 points. A higher score indicates better quality. Articles with $\geq 3$ points were considered to have high quality. ${ }^{15}$

\section{Statistical analyses}

We assessed the overall efficacy of adding panitumumab to chemotherapy in the treatment of patients with mCRC based on the data from the included studies. PFS and OS were treated as time-to-event variables, and thus were expressed as HRs with 95\% CIs for each study. The ORR and incidence of adverse events were treated as dichotomous variables and were expressed as risk ratios (RRs) with 95\% CIs for each study. Heterogeneity across the studies was tested using $I^{2}$ statistics, which quantitatively measured the degree of inconsistency across studies. $I^{2}$ values of $<25 \%$, approximately $50 \%$, approximately $75 \%$, and approximately $100 \%$ indicated no, low, moderate, and high heterogeneity, respectively. ${ }^{16} \mathrm{~A}$ fixedeffects model (Mantel-Haenszel method) ${ }^{17}$ was used, whereas a random-effects model (DerSimonian-Laird method) ${ }^{18}$ was used when significant heterogeneity existed $\left(I^{2}>50 \%\right)$. A subgroup analysis was conducted on the basis of $K R A S$ status and chemotherapeutic partners. The presence of publication bias was assessed using the Begg's test. ${ }^{19}$ A $P$-value of less than 0.05 was considered statistically significant. All statistical analyses were conducted using STATA software version 12.0 (StataCorp LP, College Station, TX, USA). 


\section{Results}

\section{Identification of eligible studies}

The initial search of the PubMed, Embase, and Web of Science databases yielded 566 relevant publications. Of these, 39 were excluded for duplicate records, and 458 were excluded after reviewing the title or abstract, leaving 69 articles for full-text review. In the review, eleven articles were excluded for the following reasons: one study used panitumumab in both arms,${ }^{20}$ one study used bevacizumab and panitumumab in the intervention arm, ${ }^{21}$ three studies presented preliminary outcomes, ${ }^{12,13,22}$ and six articles had single-arm study designs. ${ }^{23-28}$ Finally, four studies ${ }^{29-32}$ that met the inclusion criteria were included in this meta-analysis. The flowchart of the search strategy is shown in Figure 1.

\section{Study characteristics and quality assessment}

The main characteristics of the four RCTs included in the meta-analysis are presented in Table 1 . These studies were published between 2008 and 2014. The sample sizes of the studies ranged from 427 to 1,096 patients (total, 3,066 patients). The clinical characteristics were generally balanced between the intervention and control arms of each study. The four studies tested the KRAS mutation status of the tumors using allele-specific polymerase chain reaction. Adverse events were graded using the common Terminology Criteria for Adverse Events (version 3.0) with modifications for specific skin- and nail-related toxicities. ${ }^{33}$ The median Jadad score of the included studies was 3 (range: $3-4$ ).

\section{Primary outcome: PFS}

All the four RCTs reported PFS in the study patients. The aggregated results of these studies suggested that the addition of panitumumab to chemotherapy significantly prolonged PFS in the treatment of patients with $\mathrm{mCRC}$ ( $\mathrm{HR}=0.84$, 95\% CI $=0.78-0.91, P=0.000$ ) (Figure 2). Begg's test and the funnel plot revealed no evidence of obvious publication bias $(Z=0.707, P=0.946)$. Meanwhile, significant heterogeneity was identified $\left(I^{2}=83.6 \%, P=0.00\right)$. Subsequently, we performed subgroup analyses to explore potential sources of heterogeneity.

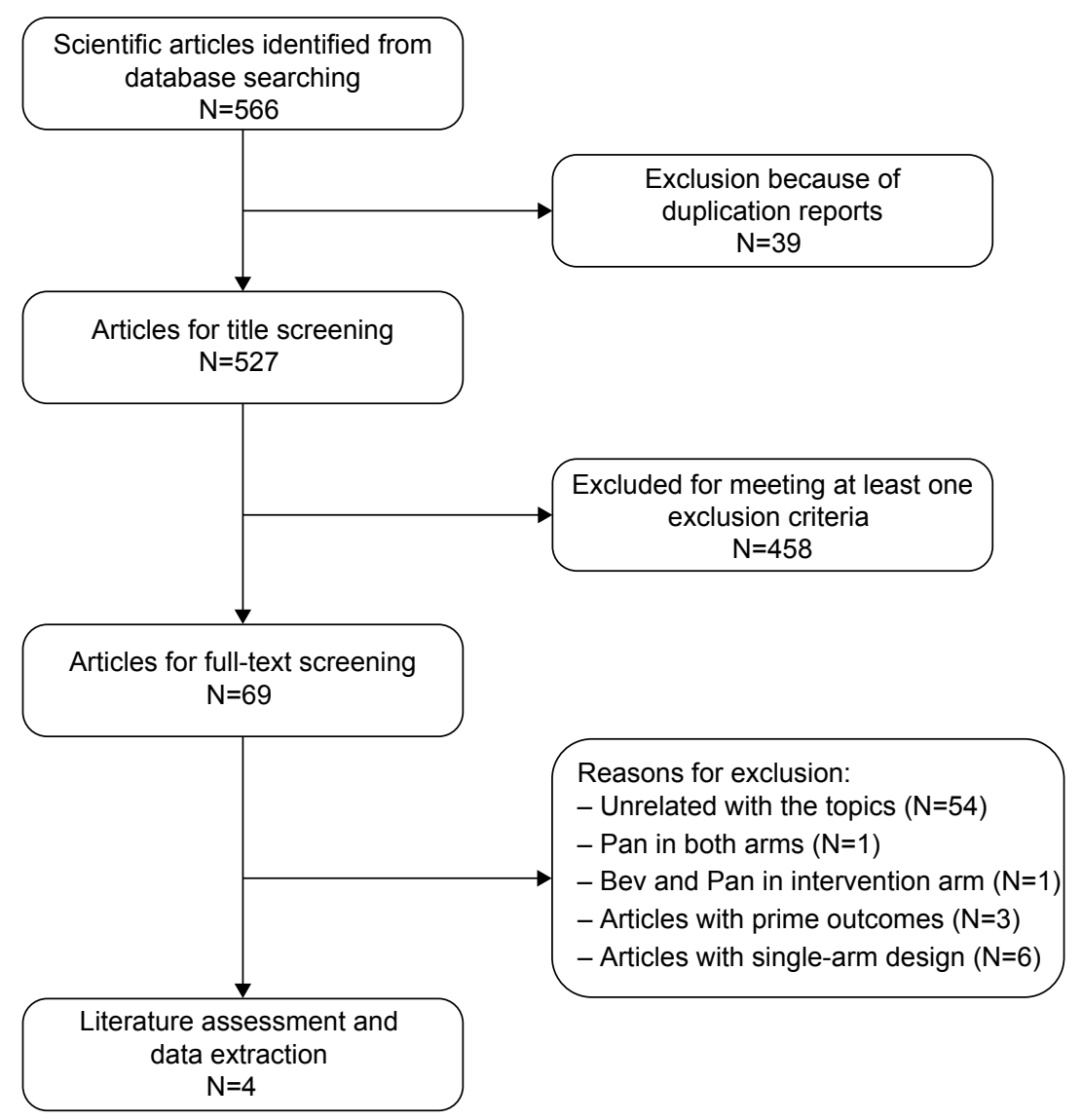

Figure I Eligibility of studies for inclusion in the meta-analysis. Abbreviations: Bev, bevacizumab; Pan, panitumumab. 
Table I Characteristics of the studies included in the meta-analysis

\begin{tabular}{|c|c|c|c|c|c|c|c|c|}
\hline Study & $\begin{array}{l}\text { Treatment } \\
\text { group }\end{array}$ & $\begin{array}{l}\text { Number } \\
\text { of patients }\end{array}$ & $\begin{array}{l}\text { Median age } \\
\text { (range) }\end{array}$ & $\begin{array}{l}\text { Malel } \\
\text { female }\end{array}$ & $\begin{array}{l}\text { WHO } \\
\text { performance } \\
\text { status }(0 / 1 / 2+)\end{array}$ & $\begin{array}{l}\text { Median follow-up } \\
\text { (months) }\end{array}$ & $\begin{array}{l}\text { Line of } \\
\text { treatment }\end{array}$ & $\begin{array}{l}\text { Jadac } \\
\text { score }\end{array}$ \\
\hline \multirow[t]{2}{*}{$\begin{array}{l}\text { Amado } \\
\text { et }\left.\right|^{29}\end{array}$} & $\begin{array}{l}\text { Panitumumab + } \\
\text { BSC }\end{array}$ & 208 & $62.5(29-82) *$ & $130 / 78$ & $96 / 84 / 28$ & Not reported & $\begin{array}{l}\text { Not } \\
\text { reported }\end{array}$ & 3 \\
\hline & BSC & 219 & $63.0(32-8 \mathrm{I})^{*}$ & $140 / 79$ & $77 / 109 / 33$ & & & \\
\hline \multirow[t]{2}{*}{$\begin{array}{l}\text { Douillard } \\
\text { et } \mathrm{al}^{30}\end{array}$} & $\begin{array}{l}\text { Panitumumab + } \\
\text { FOLFOX4 }\end{array}$ & 546 & $62(27-85)^{*}$ & $362 / 184$ & $518^{a} / 28^{b}$ & 20 & First line & 4 \\
\hline & FOLFOX4 & 550 & $61(33-83)^{*}$ & $332 / 218$ & $521^{\mathrm{a} / 28^{\mathrm{b}}}$ & & & \\
\hline \multirow[t]{2}{*}{$\begin{array}{l}\text { Peeters } \\
\text { et } \mathrm{al}^{31}\end{array}$} & $\begin{array}{l}\text { Panitumumab + } \\
\text { FOLFIRI }\end{array}$ & 541 & $60(28-84)^{*}$ & $321 / 220$ & $512^{a} / 29^{b}$ & 30 & Second line & 3 \\
\hline & FOLFIRI & 542 & $61(29-86)^{*}$ & $339 / 203$ & $506^{a} / 36^{b}$ & & & \\
\hline \multirow[t]{2}{*}{$\begin{array}{l}\text { Seymour } \\
\text { et } \mathrm{a}^{32}\end{array}$} & $\begin{array}{l}\text { Panitumumab + } \\
\text { irinotecan }\end{array}$ & 230 & $64(57-70)$ & $160 / 70$ & $217^{a} / 13^{b}$ & 25.4 & $\begin{array}{l}\text { Not } \\
\text { reported }\end{array}$ & 3 \\
\hline & Irinotecan & 230 & $63(56-69)$ & $158 / 72$ & $217^{a} / 13^{b}$ & & & \\
\hline
\end{tabular}

Notes: *Data from wild-type patients. ${ }^{\mathrm{a} D a t a}$ from patients with an ECOG performance status of 0-I. 'bata from patients with an ECOG performance status of 2.

Abbreviations: BSC, best supportive care; ECOG, Eastern Cooperative Oncology Group; FOLFIRI, fluorouracil, leucovorin, and irinotecan; FOLFOX4, infusional fluorouracil, leucovorin, and oxaliplatin; WHO, World Health Organization.

Subgroup analyses were conducted on the basis of $K R A S$ status (wild-type or mutant KRAS). The results demonstrated a $29 \%$ reduction in the risk of progression with the addition of panitumumab to chemotherapy ( $\mathrm{HR}=0.71$, $95 \% \mathrm{CI}=0.57-0.88, P=0.002$; heterogeneity test: $P^{2}=79.9 \%$, $P=0.002$ ) in patients with wild-type $K R A S$ tumors (Figure 3). However, no beneficial effect was found in patients with KRAS-mutant tumors (HR $=1.06,95 \% \mathrm{CI}=0.87-1.31$, $P=0.420$; heterogeneity test: $P^{2}=58.9 \%, P=0.088$ ).

Subgroup analyses were performed on the basis of the use of oxaliplatin-based chemotherapy and irinotecan-based chemotherapy. Pooled results illustrated that irinotecanbased chemotherapy significantly improved PFS (HR $=0.84$, $95 \%$ CI $=0.76-0.94, P=0.002$ ), whereas oxaliplatin-based chemotherapy had no effect $(\mathrm{HR}=1.05,95 \% \mathrm{CI}=0.74-1.48$, $P=0.781$ ).

\section{Secondary outcomes: OS and ORR} Overall survival

All the four RCTs reported OS data. Pooled results revealed that adding panitumumab to chemotherapy did not significantly improve OS (HR $=0.97,95 \%$ CI $=0.89-1.05$, $P=0.402$ ) (Figure 4). Begg's test and the funnel plot revealed no evidence of obvious publication bias $(Z=0.06$, $P=0.07)$.

Moreover, subgroup analyses identified no statistically significant improvement in OS in the subgroup of patients with wild-type KRAS tumors (HR $=0.94,95 \%$

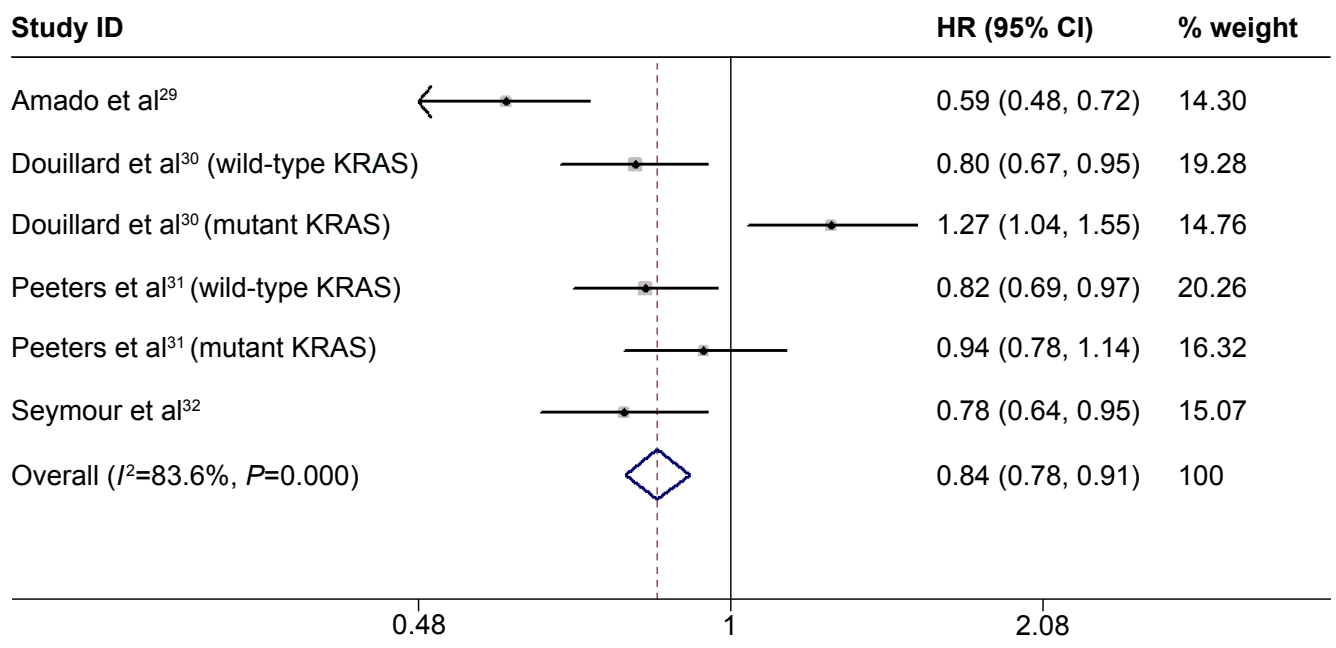

Figure 2 Meta-analysis exploring the effect of adding panitumumab to chemotherapy on progression-free survival. Abbreviations: $\mathrm{Cl}$, confidence interval; $\mathrm{HR}$, hazard ratio. 


\begin{tabular}{|c|c|c|}
\hline Study ID & $\mathrm{HR}(95 \% \mathrm{Cl})$ & $\%$ weight \\
\hline \multicolumn{3}{|l|}{ Wild-type KRAS } \\
\hline Amado et $\mathrm{al}^{29}$ & $0.45(0.34,0.59)$ & 21.32 \\
\hline Douillard et al ${ }^{30}$ & $0.80(0.67,0.95)$ & 26.54 \\
\hline Peeters et $\mathrm{al}^{31}$ & $0.82(0.69,0.97)$ & 26.76 \\
\hline Seymour et al ${ }^{32}$ & $0.78(0.64,0.95)$ & 25.38 \\
\hline Subtotal $\left(I^{2}=79.9 \%, P=0.002\right)$ & $0.71(0.57,0.88)$ & 100 \\
\hline \multicolumn{3}{|l|}{ Mutant KRAS } \\
\hline Amado et $\mathrm{al}^{29}$ & $0.99(0.73,1.36)$ & 24.60 \\
\hline Douillard et al ${ }^{30}$ & $1.27(1.04,1.55)$ & 37.05 \\
\hline Peeters et $\mathrm{al}^{31}$ & $0.94(0.78,1.14)$ & 38.35 \\
\hline Subtotal $\left(I^{2}=58.9 \%, P=0.088\right)$ & $1.06(0.87,1.31)$ & 100 \\
\hline
\end{tabular}

Figure 3 Subgroup analyses of progression-free survival based on KRAS mutation status. Note: Weights are from random effects analysis.

Abbreviations: $\mathrm{Cl}$, confidence interval; $\mathrm{HR}$, hazard ratio.

$\mathrm{CI}=0.85-1.04, P=0.216)$. Nonsignificant results were observed for both irinotecan-based chemotherapy $(\mathrm{HR}=0.95$, $95 \% \mathrm{CI}=0.85-1.06, P=0.340)$ and oxaliplatin-based chemotherapy $(\mathrm{HR}=1.01,95 \% \mathrm{CI}=0.76-1.34, P=0.944)$.

\section{Overall response rate}

All the four RCTs reported ORR data. The pooled analysis using a random-effects model indicated that adding panitumumab to chemotherapy significantly increased ORR $(\mathrm{RR}=2.18,95 \% \mathrm{CI}=1.13-4.22, P=0.021)$ (Figure 5). In the subgroup analysis, a similar outcome was found in patients with wild-type $K R A S$ tumors $(\mathrm{RR}=2.43,95 \% \mathrm{CI}=1.21-4.90$,
$P=0.013$ ), but not in patients with mutant KRAS tumors (RR $=0.99,95 \% \mathrm{CI}=0.81-1.20, P=0.894)$. The assessment of publication bias revealed no potential publication bias among the included studies $(Z=0.734, P=0.132)$.

\section{Adverse events}

All the four RCTs reported the occurrence of adverse events. The pooled estimate calculated using a random-effects model demonstrated that the combination of panitumumab and chemotherapy was associated with significantly increased incidence rates of grade 3/4 skin toxicity $(\mathrm{RR}=19.79$, $95 \% \mathrm{CI}=12.65-30.95, P=0.00)$, hypokalemia $(\mathrm{RR}=3.31$,

\begin{tabular}{|c|c|c|}
\hline Study ID & HR (95\% Cl) & $\%$ weight \\
\hline Amado et al ${ }^{29}$ & $0.97(0.79,1.18)$ & 15.26 \\
\hline Douillard et al ${ }^{30}$ (wild-type KARS) & $0.88(0.73,1.06)$ & 17.66 \\
\hline Douillard et $\mathrm{al}^{30}$ (mutant KARS) & $1.17(0.95,1.45)$ & 13.74 \\
\hline Peeters et al ${ }^{31}$ (wild-type KARS) & $0.92(0.78,1.10)$ & 20.78 \\
\hline Peeters et $\mathrm{al}^{31}$ (mutant KARS) & $0.93(0.77,1.13)$ & 16.69 \\
\hline Seymour et al ${ }^{32}$ & $1.01(0.83,1.23)$ & 15.87 \\
\hline Overall $\left(I^{2}=0.0 \%, P=0.444\right)$ & $0.97(0.89,1.05)$ & 100 \\
\hline
\end{tabular}

Figure 4 Meta-analysis exploring the effect of adding panitumumab to chemotherapy on overall survival. Abbreviations: $\mathrm{Cl}$, confidence interval; $\mathrm{HR}$, hazard ratio. 


\begin{tabular}{|c|c|c|c|}
\hline Study ID & & $\operatorname{RR}(95 \% \mathrm{CI})$ & $\%$ weight \\
\hline Amado et $\mathrm{a}^{29}$ & & $37.46(2.28,614.89)$ & 4.77 \\
\hline Douillard et al ${ }^{30}$ & + & $1.12(0.99,1.27)$ & 33.30 \\
\hline Peeters et $\mathrm{al}^{31}$ & 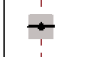 & $2.17(1.65,2.84)$ & 31.88 \\
\hline Seymour et $\mathrm{al}^{32}$ & $\div$ & $2.93(1.97,4.35)$ & 30.05 \\
\hline Overall $\left(I^{2}=93.3 \%, P=0.000\right)$ & & $2.18(1.13,4.22)$ & 100 \\
\hline
\end{tabular}

Figure 5 Meta-analysis exploring the effect of adding panitumumab to chemotherapy on the objective response rate. Note: Weights are from random effects analysis.

Abbreviations: $\mathrm{Cl}$, confidence interval; $\mathrm{RR}$, risk ratio.

95\% CI $=1.31-8.35, P=0.011)$, mucositis $(\mathrm{RR}=3.52,95 \%$ $\mathrm{CI}=1.84-6.77, P=0.00)$, hypomagnesemia $(\mathrm{RR}=18.79$, 95\% CI $=5.90-59.84, P=0.00)$, diarrhea $(\mathrm{RR}=1.71,95 \%$ $\mathrm{CI}=1.19-2.47, P=0.004)$, and fatigue $(\mathrm{RR}=2.02,95 \%$ $\mathrm{CI}=1.30-3.15, P=0.002)$.

\section{Discussion}

The current meta-analysis suggested that, compared with chemotherapy alone, the combination of panitumumab and chemotherapy significantly improved PFS ( $\mathrm{HR}=0.84$, 95\% CI $=0.78-0.91, P=0.000)$ and ORR $(\mathrm{RR}=2.18$, 95\% CI $=1.13-4.22, P=0.021)$, but it did not prolong OS (HR $=0.97,95 \% \mathrm{CI}=0.89-1.05, P=0.402)$. Additionally, in the subgroup analysis, a PFS benefit was observed in the wild-type $K R A S$ population $(\mathrm{HR}=0.71,95 \% \mathrm{CI}=0.57-0.88$, $P=0.002)$, but not in the mutant $K R A S$ population $(\mathrm{HR}=1.06$, 95\% CI $=0.87-1.31, P=0.420)$. Similarly, the addition of panitumumab to irinotecan-based chemotherapy significantly prolonged PFS compared to chemotherapy alone $(\mathrm{HR}=0.84$, 95\% CI $=0.76-0.94, P=0.002)$. By contrast, the addition of panitumumab to oxaliplatin-based chemotherapy conferred no significant benefit concerning PFS (HR $=1.05$, 95\% $\mathrm{CI}=0.74-1.48, P=0.781)$.

According to this meta-analysis, patients receiving the combination of panitumumab and chemotherapy experienced significantly prolonged PFS compared to patients treated with chemotherapy alone. However, this significant benefit was not achieved when panitumumab was added to bevacizumab-based chemotherapy. In the RCT conducted by Hecht et $\mathrm{al}^{21}$ patients were randomly assigned to receive bevacizumab-based chemotherapy with or without panitumumab, and panitumumab-treated patients displayed decreased PFS (HR $=1.27,95 \% \mathrm{CI}=1.06-1.52)$. Although the exact explanation for this result is not clear, the authors postulated several plausible hypotheses: 1) the existence of pharmacokinetic interactions between antibodies or between antibodies and chemotherapy; 2) toxicity was exacerbated by dual-pathway inhibition in the combination arm; and 3) the toxicity induced by the anti-EGFR antibodies and chemotherapy resulted in dose delays and reductions and increased the risk of death in the panitumumab arm. ${ }^{21}$

In this meta-analysis, we found that irinotecan-based regimens significantly prolonged PFS in the treatment of mCRC. However, this beneficial effect was not found for oxaliplatin-based regimens. The reason why panitumumab is better paired with irinotecan than with other drugs remains unknown. In a recently published meta-analysis conducted by Zhou et al, ${ }^{34}$ cetuximab and panitumumab were found to have different effects when combined with different fluoropyrimidine regimens. The authors hypothesized that the addition of cetuximab may have reduced the dose intensity and thus affected the efficacy of capecitabinebased therapy.

Skin toxicity is a class effect of anti-EGFR treatment for both monoclonal antibodies and tyrosine kinase inhibitors. ${ }^{35,36}$ The development of skin toxicity is considered a predictive factor of clinical efficacy. Among panitumumab-treated patients, prolonged PFS and OS and a higher ORR are usually observed in those who develop grade 2-4 skin toxicity compared with those without skin toxicity. However, although the appearance of skin toxicity indicated the on-target activity associated with clinical benefits, it was also found in patients who did not benefit from treatment.

Some potential limitations in this meta-analysis should be considered. First, the data we abstracted were obtained 
from publications rather than individual patient data, making them less powerful for confirming the findings. ${ }^{37}$ However, according to the results of a correlation analysis, ${ }^{38}$ metaanalyses based on abstract data are strongly correlated with those based on individual patient data, indicating that abstract data are acceptable and that they could be used in place of individual patient data. Second, there was considerable heterogeneity among the included studies. The characteristics of the targeted populations, study designs, treatment schedules, and follow-up intervals varied greatly. All of these factors may lead to heterogeneity and potentially affect our results. Third, although we included all large trials assessing the efficacy of panitumumab plus chemotherapy in the treatment of patients with $\mathrm{mCRC}$, caution should be taken when interpreting the results, as the analysis was based on a limited number of RCTs.

In conclusion, this meta-analysis confirmed the effects, as well as the acceptable safety profile, of adding panitumumab to chemotherapy on PFS and ORR in the treatment of patients with wild-type KRAS mCRC. However, considering the limited number of RCTs and the heterogeneity among the included studies, larger, better-designed RCTs are needed to substantiate the findings and investigate the predictive role of $K R A S$ concerning the combination of panitumumab and chemotherapy for patients with $\mathrm{mCRC}$.

\section{Disclosure}

The authors report no conflicts of interest in this work.

\section{References}

1. Parkin DM, Bray F, Ferlay J, Pisani P. Global cancer statistics, 2002. CA Cancer J Clin. 2005;55:74-108.

2. Wolpin BM, Mayer RJ. Systemic treatment of colorectal cancer. Gastroenterology. 2008;134:1296-1310.

3. O'Neil BH, Goldberg RM. Innovations in chemotherapy for metastatic colorectal cancer: an update of recent clinical trials. Oncologist. 2008; 13:1074-1083.

4. Kopetz S, Chang GJ, Overman MJ, et al. Improved survival in metastatic colorectal cancer is associated with adoption of hepatic resection and improved chemotherapy. J Clin Oncol. 2009;27:3677-3683.

5. Chau I, Cunningham D. Treatment in advanced colorectal cancer: what, when and how? Br J Cancer. 2009;100:1704-1719.

6. Simmonds PC. Palliative chemotherapy for advanced colorectal cancer: systematic review and meta-analysis. Colorectal Cancer Collaborative Group. BMJ. 2000;321:531-535.

7. Labianca RF, Beretta GD, Pessi MA. Disease management considerations: disease management considerations. Drugs. 2001;61: 1751-1764.

8. Labianca R, Pessi MA, Zamparelli G. Treatment of colorectal cancer. Current guidelines and future prospects for drug therapy. Drugs. 1997; 53:593-607.

9. Midgley R, Kerr D. Colorectal cancer. Lancet. 1999;353:391-399.

10. Ortega J, Vigil CE, Chodkiewicz C. Current progress in targeted therapy for colorectal cancer. Cancer Control. 2010;17:7-15.

11. Banck MS, Grothey A. Biomarkers of resistance to epidermal growth factor receptor monoclonal antibodies in patients with metastatic colorectal cancer. Clin Cancer Res. 2009;15:7492-7501.
12. Douillard JY, Siena S, Cassidy J, et al. Randomized, phase III trial of panitumumab with infusional fluorouracil, leucovorin, and oxaliplatin (FOLFOX4) versus FOLFOX4 alone as first-line treatment in patients with previously untreated metastatic colorectal cancer: the PRIME study. J Clin Oncol. 2010;28:4697-4705.

13. Peeters M, Price TJ, Cervantes A, et al. Randomized phase III study of panitumumab with fluorouracil, leucovorin, and irinotecan (FOLFIRI) compared with FOLFIRI alone as second-line treatment in patients with metastatic colorectal cancer. J Clin Oncol. 2010;28:4706-4713.

14. Jadad AR, Moore RA, Carroll D, et al. Assessing the quality of reports of randomized clinical trials: is blinding necessary? Control Clin Trials. $1996 ; 17: 1-12$

15. Kjaergard LL, Villumsen J, Gluud C. Reported methodologic quality and discrepancies between large and small randomized trials in metaanalyses. Ann Inter Med. 2001;135:982-989.

16. Higgins JP, Thompson SG, Deeks JJ, Altman DG. Measuring inconsistency in meta-analyses. BMJ. 2003;327:557-560.

17. DerSimonian R, Laird N. Meta-analysis in clinical trials. Control Clin Trials. 1986;7:177-188.

18. Vangel MG, Rukhin AL. Maximum likelihood analysis for heteroscedastic one-way random effects ANOVA in interlaboratory studies. Biometrics. 1999;55:129-136.

19. Begg CB, Mazumdar M. Operating characteristics of a rank correlation test for publication bias. Biometrics. 1994;50:1088-1101.

20. Mitchell EP, Piperdi B, Lacouture ME, et al. The efficacy and safety of panitumumab administered concomitantly with FOLFIRI or Irinotecan in second-line therapy for metastatic colorectal cancer: the secondary analysis from STEPP (Skin Toxicity Evaluation Protocol With Panitumumab) by KRAS status. Clin Colorectal Cancer. 2011;10:333-339.

21. Hecht JR, Mitchell E, Chidiac T, et al. A randomized phase IIIB trial of chemotherapy, bevacizumab, and panitumumab compared with chemotherapy and bevacizumab alone for metastatic colorectal cancer. J Clin Oncol. 2009;27:672-680.

22. Van Cutsem E, Peeters M, Siena S, et al. Open-label phase III trial of panitumumab plus best supportive care compared with best supportive care alone in patients with chemotherapy-refractory metastatic colorectal cancer. J Clin Oncol. 2007;25:1658-1664.

23. Berlin J, Posey J, Tchekmedyian S, et al. Panitumumab with irinotecan/ leucovorin/5-fluorouracil for first-line treatment of metastatic colorectal cancer. Clin Colorectal Cancer. 2007;6:427-432.

24. Hecht JR, Patnaik A, Berlin J, et al. Panitumumab monotherapy in patients with previously treated metastatic colorectal cancer. Cancer. 2007; 110:980-988.

25. Kohne CH, Hofheinz R, Mineur L, et al. First-line panitumumab plus irinotecan/5-fluorouracil/leucovorin treatment in patients with metastatic colorectal cancer. J Cancer Res Clin Oncol. 2012;138:65-72.

26. Cohn AL, Shumaker GC, Khandelwal P, et al. An open-label, singlearm, phase 2 trial of panitumumab plus FOLFIRI as second-line therapy in patients with metastatic colorectal cancer. Clin Colorectal Cancer. 2011;10:171-177.

27. van Hellemond IE, Creemers GJ, van Warmerdam LJ, de Jong FA, Koornstra RH. Panitumumab monotherapy as a second-line treatment in metastasised colorectal cancer: a single centre experience. Clin Oncol (R Coll Radiol). 2014;26:135-141.

28. Van Cutsem E, Siena S, Humblet Y, et al. An open-label, single-arm study assessing safety and efficacy of panitumumab in patients with metastatic colorectal cancer refractory to standard chemotherapy. Ann Oncol. 2008;19:92-98.

29. Amado RG, Wolf M, Peeters M, et al. Wild-type KRAS is required for panitumumab efficacy in patients with metastatic colorectal cancer. J Clin Oncol. 2008;26:1626-1634.

30. Douillard JY, Siena S, Cassidy J, et al. Final results from PRIME: randomized phase III study of panitumumab with FOLFOX4 for firstline treatment of metastatic colorectal cancer. Ann Oncol. 2014;25: 1346-1355.

31. Peeters M, Price TJ, Cervantes A, et al. Final results from a randomized phase 3 study of FOLFIRI $\{+/-\}$ panitumumab for second-line treatment of metastatic colorectal cancer. Ann Oncol. 2014;25:107-116. 
32. Seymour MT, Brown SR, Middleton G, et al. Panitumumab and irinotecan versus irinotecan alone for patients with KRAS wild-type, fluorouracil-resistant advanced colorectal cancer (PICCOLO): a prospectively stratified randomised trial. Lancet Oncol. 2013;14:749-759.

33. Cancer Therapy Evaluation Program. Common Terminology Criteria for Adverse Events, Version 3.0. Bethesda, MD: Division of Cancer Treatment and Diagnosis, National Cancer Institute, National Institutes of Health, Department of Health and Human Services; 2006.

34. Zhou SW, Huang YY, Wei Y, et al. No survival benefit from adding cetuximab or panitumumab to oxaliplatin-based chemotherapy in the first-line treatment of metastatic colorectal cancer in KRAS wild type patients: a meta-analysis. PloS One. 2012;7:e50925.

35. Orditura M, De Vita F, Galizia G, et al. Correlation between efficacy and skin rash occurrence following treatment with the epidermal growth factor receptor inhibitor cetuximab: a single institution retrospective analysis. Oncol Rep. 2009;21:1023-1028.
36. Racca P, Fanchini L, Caliendo V, et al. Efficacy and skin toxicity management with cetuximab in metastatic colorectal cancer: outcomes from an oncologic/dermatologic cooperation. Clin Colorectal Cancer. 2008;7:48-54.

37. Stewart LA, Parmar MK. Meta-analysis of the literature or of individual patient data: is there a difference? Lancet. 1993;341:418-422.

38. Bria E, Gralla RJ, Raftopoulos H, Giannarelli D. Comparing two methods of meta-analysis in clinical research-individual patient data-based (IPD) and literature-based abstracted data (AD) methods: analyzing five oncology issues involving more than 10,000 patients in randomized clinical trials (RCTs). J Clin Oncol. 2007;25: abstr 6512.

\section{Publish your work in this journal}

Drug Design, Development and Therapy is an international, peerreviewed open-access journal that spans the spectrum of drug design and development through to clinical applications. Clinical outcomes, patient safety, and programs for the development and effective, safe, and sustained use of medicines are a feature of the journal, which has also been accepted for indexing on PubMed Central. The manuscript management system is completely online and includes a very quick and fair peer-review system, which is all easy to use. Visit http://www.dovepress.com/testimonials.php to read real quotes from published authors.

Submit your manuscript here: http://www.dovepress.com/drug-design-development-and-therapy-journal 